\title{
AVALIAÇÃO DAS BOAS PRÁTICAS DE FABRICAÇÃo EM PANIFICADORAS POR MEIO DA APLICABILIDADE DE CHECK-LIST NO MUNICÍPIO DE CAMPINAS - SP
}

Evaluation of good practices of bakery manufacturing through checklist applicability in the municipality of Campinas - SP

\author{
Gabriela Galante Machadoํㅡ, Vanessa Fernandes Coutinho², Renato Ribeiro Nogueira \\ Ferraz $^{3}$ \\ ${ }^{1-3}$ Universidade Estácio de Sá - SP.
}

\section{RESUMO}

Nos últimos anos, observou-se a expansão de diversos setores na área de alimentação, sendo as panificadoras um dos que mais cresceram em todo o mundo. Portanto, devido a este crescimento tão promissor, surgiram às preocupações com a qualidade higiênicosanitária das padarias. Desta forma, o objetivo principal deste estudo foi avaliar as boas práticas de fabricação em duas panificadoras localizadas no Município de Campinas-SP. O instrumento utilizado para coleta dos dados foi uma lista de verificação (check-list) disponibilizada na resolução - RDC $n^{\circ}$ 275/2002, que conta com diversificados itens de verificação, divididos em cinco módulos: I- Edificações e Instalações; II - Equipamentos móveis e Utensílios; III - Manipuladores; IV - Produção e Transporte do Alimento e V - Documentação. Após a aplicação da lista de verificação, cinco perguntas elaboradas e padronizadas para ambos os estabelecimentos, foram realizadas aos proprietários, a fim de elucidar as inconformidades encontradas. Deste modo, os resultados obtidos apontaram diversas não conformidades nos estabelecimentos avaliados, sendo a padaria $\mathrm{B}$ a de pior atendimento as boas práticas de fabricação, tanto ao ser avaliada e classificada de forma geral, como ao ser avaliada individualmente em seus módulos, quando comparada a padaria A, embora nenhuma das panificadoras tenham sido classificadas em Grupo 1 - BOM, considerando o de melhor atendimento as boas práticas de fabricação. Conclui-se então que ambos os locais não apresentam adequação as boas práticas e por isso, colocam em risco a saúde de seus consumidores.

Palavras chave: Padarias, Boas práticas, Check-List, Condições higiênico-sanitárias, Segurança alimentar, Legislação.

\footnotetext{
ABSTRACT

In recent years, the expansion of various sectors in the area of food has been observed, with bakeries being one of the most growing in the world. Therefore, due to this promising growth, concerns were raised about the hygienic-sanitary quality of bakeries. In this way, the main objective of this study was to evaluate the good manufacturing practices in two bakeries located in the city of Campinas-SP. The instrument used for data collection was a checklist available in Resolution RDC $n^{\circ}$ 275/2002, which has several verification items, divided into five modules: I - Buildings and Facilities; II - Mobile equipment and utensils; III - Manipulators; IV - Food Production and Transport and V - Documentation. After applying the checklist, five questions developed and standardized for both establishments were made to the owners in order to elucidate the nonconformities found. In this way, the obtained results pointed out several nonconformities in the evaluated establishments, being the bakery B the one of worse attendance the good practices of manufacture, as much when being evaluated and classified in general form, as when being evaluated individually in its modules, when compared to bakery A, although none of the
} 
bakeries have been classified in Group 1 - BOM, considering the best attendance the good manufacturing practices. It is concluded that both sites do not present good practices and therefore pose a risk to the health of their consumers.

Keywords: Bakeries, Good practices, Check-List, Hygiene and sanitary conditions, Food safety, Legislation.

\section{INTRODUÇÃO}

A ciência da nutrição tem por objetivo estudar a composição dos alimentos e as necessidades nutricionais de cada indivíduo, por isso, a ingestão de alimentos adequados se faz necessária para o desempenho das funções vitais de cada ser. Consequentemente, verifica-se a importância do controle higiênico-sanitário nos serviços de alimentação para garantia da qualidade dos produtos preparados, permitindo que estes estejam livres de contaminações e que sejam ainda uma excelente fonte nutricional, essencial à saúde humana (DOS SANTOS et al., 2010; FERRAZ et al., 2014).

Uma unidade de alimentação e nutrição (UAN), por exemplo, tem como principal objetivo a produção de refeições pautadas na segurança alimentar, pois preconiza um alimento seguro, livre de contaminantes (COELHO et al., 2015; COUTO et al., 2005). Contudo, a manutenção da saúde de todo indivíduo depende da ingestão de alimentos quantitativamente e qualitativamente adequados e saudáveis que não ocasionem riscos a sua saúde, pois em sua visão, qualidade alimentar engloba não só as características de sabor, aroma, aparência, textura e padronização, mais também a preocupação na aquisição de alimentos adequados (APLEVICZ; SANTOS; BORTOLOZO, 2010; GUIMARÃES; FIGUEIREDO, 2010). Entretanto, para garantia desta segurança alimentar diversos itens devem ser considerados, dentre eles as instalações das unidades, que devem ser projetadas de forma a permitir um fluxo contínuo das etapas produtivas, além de outras medidas efetivas que venham evitar contaminações cruzadas. Portanto, se faz necessário o estabelecimento de normas que garantam a devida inspeção, fiscalização e vigilância dos estabelecimentos alimentícios, a fim de assegurar a qualidade dos alimentos e consequentemente garantir sua segurança nutricional. Desta maneira, uma das formas para atingir este padrão de qualidade é a implantação das Boas práticas de Fabricação (BPF) (APLEVICZ; SANTOS; BORTOLOZO, 2010; DOS SANTOS et al., 2010).

A implantação e utilização das Boas Práticas de Fabricação (BPF) garante o controle da qualidade nos processos operacionais dos serviços de alimentação, permitindo com que produtos seguros sejam produzidos através da avaliação da qualidade da matériaprima, através da higienização das instalações, equipamentos, móveis e utensílios, das técnicas de manipulação dos alimentos, do controle da saúde dos funcionários, do controle da água utilizada e dos cuidados com os vetores e pragas, através de todo o controle exercido sobre os perigos químicos, físicos e biológicos que englobam a cadeia produtiva. Por isso, sua principal meta é a redução dos riscos e o aumento da segurança alimentar, tornando seu uso indispensável (APLEVICZ; SANTOS; BORTOLOZO, 2010; COUTO et al., 2005; DOS SANTOS et al., 2010).

No Brasil, a realização das refeições fora do lar tornou-se um hábito principalmente após o processo de globalização, o qual permitiu um aumento no ritmo do cotidiano da população que passou a buscar alimentos rápidos e práticos para adaptar a sua realidade. Desta forma, podemos observar uma ampliação de diversos setores de alimentação. As padarias, por exemplo, constituem um dos estabelecimentos que mais cresceram na economia brasileira ao longo dos anos, porém, reconhece-se que o seu perfil é absolutamente heterogêneo e enquanto poucos comerciantes utilizam as mais modernas tecnologias para produção de seus produtos, a maioria ainda faz uso de tecnologia 
artesanal sem as mínimas condições higiênico-sanitárias (BRAMORSKI et al., 2004; GUIMARÃES; FIGUEIREDO, 2010). Sendo assim, observa-se que a grande maioria não considera que o processo de panificação em suas várias etapas apresentam diferentes exigências técnicas ambientais, principalmente com relação à temperatura ambiental e em geral executam atividades distintas onde além de panificadoras e confeitarias, estes estabelecimentos são bar e lanchonete, mercearia e casa de frios, dividindo o mesmo espaço físico, frequentemente insuficiente para tal diversidade (CARDOSO, L.; ARAÚJO, 2001; GERMANO et al., 2009).

Logo, com a crescente valorização do setor é essencial que as panificadoras busquem se destacar por meio da melhoria da qualidade de seus produtos, garantindo assim um controle higiênico-sanitário mais eficiente durante a fabricação. Desta maneira, estas devem seguir inicialmente as leis e documentações estabelecidas pelo órgão físcal de Vigilância Sanitária (VISA), onde podemos destacar a implantação do Manual de boas práticas de fabricação e dos procedimentos operacionais padronizados, documentos estes, que tem por objetivo auxiliar o estabelecimento no atendimento as boas práticas de fabricação necessárias para o adequado processamento dos alimentos, evitando assim possíveis contaminações que poderão desencadear doenças transmitidas por alimentos (DTA's) (CARDOSO, A. B. et al., 2005; DE SÃO JOSÉ; COELHO; FERREIRA, 2011).

As doenças transmitidas por alimentos (DTA's) são um dos principais problemas encontrados nas panificadoras atualmente, devido às precárias condições higiênicosanitárias dos locais de produção, aliado ao tempo prolongado de armazenamento dos grãos de trigo bem como dos produtos processados, além de práticas inadequadas de higiene pessoal e manipulação de alimentos. Ainda, nota-se que a existência de uma gama de serviços em um mesmo espaço físico também pode constituir perigo à saúde pública, por ampliar os riscos de contaminação cruzada (BRAMORSKI et al., 2004; GERMANO et al., 2009).

De acordo com estudos estatísticos da Organização Mundial de Saúde (OMS), mais de $60 \%$ dos casos de doenças transmitidas por alimentos, decorrem do descuido higiênico-sanitário dos manipuladores, das técnicas inadequadas de processamento e da deficiência de higiene da estrutura física, utensílios e equipamentos. Deste modo, o Comitê da Organização das Nações Unidas para Agricultura e Alimentação (WHO/FAO) admite que as doenças oriundas de alimentos contaminados representem a maior questão de preocupação com a saúde no mundo contemporâneo (APLEVICZ; SANTOS; BORTOLOZO, 2010; GUIMARÃES; FIGUEIREDO, 2010). Por isso, verifica-se a necessidade de um maior aperfeiçoamento das ações de controle sanitário na área de alimentos com objetivo de controlar e minimizar os riscos originados pela ingestão de alimentos contaminados (DE SÃO JOSÉ; COELHO; FERREIRA, 2011).

Sendo assim, julgou-se necessário avaliar as boas práticas de fabricação em panificadoras por meio da aplicabilidade de check-list disponibilizado na resolução RDC $n^{\circ} 275$ de 21 de Outubro de 2002, no Município de Campinas-SP, para fazer uma avaliação das condições higiênico-sanitárias destes estabelecimentos produtores de alimentos e levantar pontos críticos ou não conformidades com objetivo posterior de indagação dos proprietários das respectivas padarias a perguntas padronizadas para ambos os locais, elucidando os possíveis problemas que levaram as não conformidades encontradas buscando assim orientá-los quanto às melhorias que possam posteriormente levar a correção das não conformidades, resultando no aumento da qualidade dos produtos produzidos.

\section{OBJETIVO}


Avaliar as Boas práticas de fabricação em duas panificadoras por meio da aplicabilidade de check-list disponibilizado na resolução - RDC n ${ }^{\circ} 275$ de 21 de Outubro de 2002, no Município de Campinas-SP.

\section{MÉTODO}

Trata-se de um estudo descritivo, de levantamento, com abordagem quantitativa, qualitativa e retrospectiva, realizado no segundo semestre de 2017, sendo a amostra populacional desta pesquisa constituída por dois proprietários de duas panificadoras localizadas no Município de Campinas-SP. Nenhum critério específico de inclusão ou exclusão necessitou ser observado, sendo a escolha das panificadoras realizada de forma aleatória.

A coleta dos dados foi realizada em ambas as panificadoras em duas visitas, evitando assim possíveis falhas observacionais obtidas em uma única visita aos locais. Esta coleta foi efetuada após a autorização dos proprietários dos estabelecimentos e do comitê de ética em pesquisa (CEP) sob protocolo CAAE 78187717.3.0000.5284 e parecer de aprovação $n^{\circ} 2.376 .877$.

O instrumento utilizado para coleta dos dados nos estabelecimentos constituiu-se de uma lista de verificação (check-list) disponibilizada no anexo II da Resolução da Diretoria Colegiada - RDC n ${ }^{\circ}$ 275/2002, que dispõe diversificados itens de verificação às boas práticas de fabricação, divididos dentro dos cinco módulos: Edificações e Instalações; Equipamentos móveis e Utensílios; Manipuladores; Produção e Transporte do Alimento e Documentação.

Esta lista foi escolhida por ser um instrumento oficial, com abrangência federal e por conter itens dentro de cada módulo, necessários para uma boa avaliação higiênico sanitária dos locais estudados.

Para avaliar o nível de conformidades às boas práticas de fabricação em cada módulo analisado consideraram-se as respostas obtidas em cada item para posterior realização dos cálculos. Desta forma, as opções de respostas para o preenchimento dos itens no check-list foram: Conforme $(\mathrm{C})$ para os itens que atendiam as boas práticas de fabricação, Não Conforme (NC) para os itens que não atendiam as boas práticas de fabricação e Não se aplicam (NA) para os itens que não pertenciam aos respectivos locais, sendo então não computados para realização dos cálculos. A partir de então, o total de itens que obtiveram resposta conforme, foram somados em cada módulo individualmente para determinação do total de itens atendidos as boas práticas de fabricação, assim como o total de itens que obtiveram resposta conforme, foram somados junto ao total de itens que obtiveram resposta não conforme para determinação do total de itens julgados (conforme e não conforme), as boas práticas de fabricação.

Em seguida, tabela foi elaborada para descrição dos itens obtidos após a quantificação e em sequência os cálculos foram realizados conforme equação apresentada a seguir, para determinação do percentual de conformidades de cada módulo das panificadoras, nas respectivas visitas realizadas.

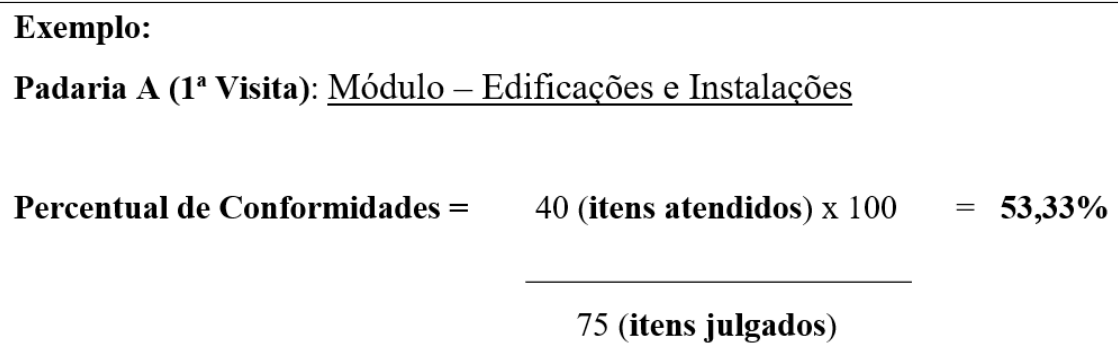


Após a utilização do cálculo mencionado, elaborou-se outra tabela para descrição da quantidade de itens conformes e não conformes de cada módulo e a representação dos percentuais $(\%)$ obtidos em cada item.

Para obtenção do resultado final de cada módulo das panificadoras avaliadas, se fez necessária à utilização de média e desvio padrão dos percentuais obtidos, uma vez que foram realizadas duas visitas em cada local. Desta forma, utilizou-se as fórmulas $=$ MEDIA e =DESVPAD.A, ambas disponíveis no Microsoft Excel 2010, onde por meio de planilha eletrônica, os resultados foram tabulados e gráfico foi elaborado, dando então o resultado final de cada módulo e sua respectiva classificação, conforme a referida resolução utilizada - RDC n 275/2002: Grupo 1 (BOM) - 76 a 100\% de atendimento aos itens (conformidade); Grupo 2 (REGULAR) - 51 a 75\% de atendimento aos itens (conformidade) e Grupo 3 (RUIM) - 0 a 50\% de atendimento aos itens (conformidade).

Para classificação geral dos dois estabelecimentos, quanto ao seu percentual de conformidades encontradas, considerou-se a somatória de todos os itens avaliados em todos os módulos. Deste modo, o total de itens julgados (conforme e não conforme) de todos os módulos foram somados, assim como o total de itens atendidos (conforme) de todos os módulos nas respectivas visitas. Após a somatória dos itens, foi realizado o mesmo cálculo demonstrado na equação anteriormente representada e o mesmo procedimento de média, desvio padrão, elaboração de tabelas e gráficos para subsequente classificação dos locais conforme seu percentual de atendimento às boas práticas de fabricação.

Para esclarecer as inconformidades encontradas, cinco perguntas padronizadas foram realizadas aos dois proprietários das duas panificadoras. Em seguida, as transcrições dos áudios das perguntas ocorreram através da utilização da ferramenta Google Cloud Speech API, para a descrição neste estudo. Sendo assim, devido à realização das perguntas foi necessária a aplicação e a autorização do Termo de Consentimento Livre e Esclarecido (TCLE).

\section{RESULTADOS}

A análise dos resultados obtidos permitiu constatar que ambos os estabelecimentos ao serem avaliados de forma geral, foram classificados em Grupo 3 "RUIM" obtendo percentuais menores que 50\% sendo este, muito inferior ao encontrado em um estudo realizado em uma unidade de alimentação e nutrição no Município de Contagem - MG, onde o local apresentou $75 \%$ de conformidades e foi classificado em Grupo 2 - "REGULAR" (DE SÃO JOSÉ; COELHO; FERREIRA, 2011). Já, ao verificar os resultados de conformidades e inconformidades, obtidos em cada módulo expresso nas respectivas padarias, podemos constatar que o módulo de manipuladoras foi o que apresentou maior percentual de conformidades às boas práticas de fabricação e o módulo de documentação o de maior percentual de inconformidades.

Inicialmente, a quantificação dos itens de cada módulo das duas panificadoras foi necessária para determinação dos itens que atendiam as boas práticas de fabricação (conformes), dos itens que não atendiam (não conformes) e daqueles itens que não se aplicavam aos locais (NA), para que então a subsequente realização dos cálculos fosse efetuada. Portanto, Tabela 1 representa esta quantificação após a aplicação do check-list. 
Tabela 1. Quantificação total dos itens avaliados após a aplicação do check-list (itens conformes), (itens não conformes), (itens que não se aplicam) e (itens julgados = conformes e não conformes) às boas práticas de fabricação, em ambas as visitas realizadas nas duas padarias analisadas no Município de Campinas-SP.

Total de itens analisados em cada módulo das respectivas padarias

\begin{tabular}{|c|c|c|c|c|c|}
\hline Padarias & Módulos & $\begin{array}{c}\text { Itens atendidos - } \\
\text { Conforme (C) } \\
\text { n }\end{array}$ & $\begin{array}{c}\text { Itens não atendidos - } \\
\text { Não conforme (NC) } \\
\text { n }\end{array}$ & $\begin{array}{c}\text { Itens que não se } \\
\text { aplicam (NA) } \\
\text { n }\end{array}$ & $\begin{array}{l}\text { Itens julgados } \\
\text { (conforme e não } \\
\text { conforme) } \\
\text { n }\end{array}$ \\
\hline \multirow[t]{5}{*}{$A-1^{a}$ visita } & $\begin{array}{l}\text { Edificações e } \\
\text { Instalações }\end{array}$ & 40 & 35 & 4 & 75 \\
\hline & $\begin{array}{l}\text { Equipamentos, } \\
\text { Móveis e Utensílios }\end{array}$ & 11 & 10 & 0 & 21 \\
\hline & Manipuladores & 10 & 4 & 0 & 14 \\
\hline & $\begin{array}{l}\text { Produção e } \\
\text { Transporte do } \\
\text { Alimento }\end{array}$ & 12 & 16 & 5 & 28 \\
\hline & Documentação & 0 & 17 & 0 & 17 \\
\hline \multirow{5}{*}{$A-2^{a}$ visita } & $\begin{array}{l}\text { Edificações e } \\
\text { Instalações }\end{array}$ & 39 & 36 & 4 & 75 \\
\hline & $\begin{array}{l}\text { Equipamentos, } \\
\text { Móveis e Utensílios }\end{array}$ & 12 & 9 & 0 & 21 \\
\hline & Manipuladores & 10 & 4 & 0 & 14 \\
\hline & $\begin{array}{l}\text { Produção e } \\
\text { Transporte do } \\
\text { Alimento }\end{array}$ & 12 & 16 & 5 & 28 \\
\hline & Documentação & 0 & 17 & 0 & 17 \\
\hline \multirow{5}{*}{$\mathrm{B}-\mathbf{1}^{\mathrm{a}}$ visita } & $\begin{array}{l}\text { Edificações e } \\
\text { Instalações }\end{array}$ & 28 & 48 & 3 & 76 \\
\hline & $\begin{array}{l}\text { Equipamentos, } \\
\text { Móveis e Utensílios }\end{array}$ & 10 & 11 & 0 & 21 \\
\hline & Manipuladores & 8 & 6 & 0 & 14 \\
\hline & $\begin{array}{l}\text { Produção e } \\
\text { Transporte do } \\
\text { Alimento }\end{array}$ & 11 & 17 & 5 & 28 \\
\hline & Documentação & 0 & 17 & 0 & 17 \\
\hline \multirow{3}{*}{$B-2^{a}$ visita } & $\begin{array}{l}\text { Edificações e } \\
\text { Instalações }\end{array}$ & 27 & 49 & 3 & 76 \\
\hline & $\begin{array}{l}\text { Equipamentos, } \\
\text { Móveis e Utensílios }\end{array}$ & 10 & 11 & 0 & 21 \\
\hline & Manipuladores & 8 & 6 & 0 & 14 \\
\hline
\end{tabular}




\begin{tabular}{llcccc}
\hline & 12 & 16 & 5 & 28 \\
\hline $\begin{array}{l}\text { Produção e } \\
\text { Alimsporte do }\end{array}$ & 0 & 17 & 0 & 17 \\
\hline Documentação & 0 & 17 & 0 \\
\hline
\end{tabular}

Fonte: Dados coletados pelo autor (2018).

Com os itens já quantificados em cada um dos módulos, considerou-se em última coluna da tabela 1 acima, o valor total de itens julgados (conforme e não conforme), excluindo-se da somatória aqueles itens que não se aplicavam (NA) aos estabelecimentos, para que então os cálculos fossem realizados e para que os percentuais de conformidades às boas práticas de fabricação fossem obtidos nas respectivas visitas. Abaixo, equação 1 representa o cálculo utilizado para obtenção dos percentuais de cada módulo das panificadoras, nas respectivas visitas realizadas:

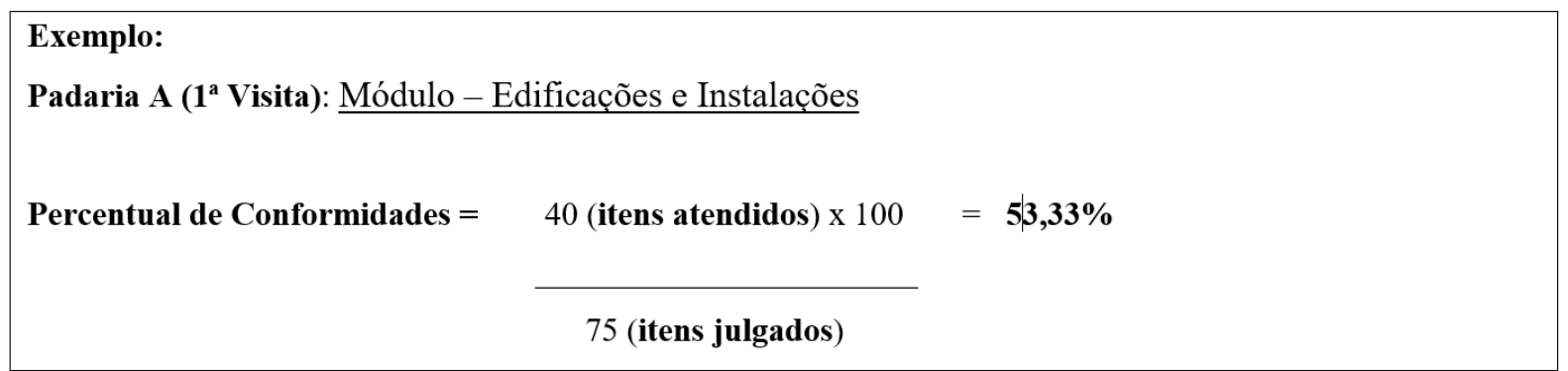

Após a realização dos cálculos, elaborou-se Tabela 2 para representar a quantidade de itens conformes e não conformes de cada módulo das respectivas padarias e o percentual encontrado em cada um deles. 
Tabela 2 - Quantidade de itens conformes e não conformes às boas práticas de fabricação em cada um dos módulos avaliados em ambas as padarias nas duas visitas realizadas e o percentual encontrado em cada um deles:

\begin{tabular}{|c|c|c|c|c|c|}
\hline \multirow[b]{2}{*}{$\underline{\text { Padarias }}$} & \multirow[b]{2}{*}{$\underline{\text { Módulos }}$} & \multicolumn{4}{|c|}{$\begin{array}{l}\text { Quantidade de itens conformes e não conformes encontrados em cada módulo e seu } \\
\text { percentual }\end{array}$} \\
\hline & & $\begin{array}{l}\text { Itens Conformes } \\
\text { (C) }\end{array}$ & $\begin{array}{l}\text { Itens conformes } \\
\text { (C) }\end{array}$ & $\begin{array}{l}\text { Itens não conformes } \\
\text { (NC) }\end{array}$ & $\begin{array}{l}\text { Itens não conformes } \\
\text { (NC) }\end{array}$ \\
\hline & & $\mathbf{n}$ & $\%$ & $\mathbf{n}$ & $\%$ \\
\hline \multirow{5}{*}{$A-1^{a}$ visita } & $\begin{array}{l}\text { Edificações e } \\
\text { Instalações }\end{array}$ & 40 & $53,33 \%$ & 35 & $46,66 \%$ \\
\hline & $\begin{array}{l}\text { Equipamentos, } \\
\text { Móveis e Utensílios }\end{array}$ & 11 & $52,38 \%$ & 10 & $47,61 \%$ \\
\hline & Manipuladores & 10 & $71,42 \%$ & 4 & $28,57 \%$ \\
\hline & $\begin{array}{l}\text { Produção e } \\
\text { Transporte do } \\
\text { Alimento }\end{array}$ & 12 & $42,85 \%$ & 16 & $57,14 \%$ \\
\hline & Documentação & 0 & $0 \%$ & 17 & $100 \%$ \\
\hline \multirow{5}{*}{$A-2^{a}$ visita } & $\begin{array}{l}\text { Edificações e } \\
\text { Instalações }\end{array}$ & 39 & $52,00 \%$ & 36 & $48,00 \%$ \\
\hline & $\begin{array}{l}\text { Equipamentos, } \\
\text { Móveis e Utensílios }\end{array}$ & 12 & $57,14 \%$ & 9 & $42,85 \%$ \\
\hline & Manipuladores & 10 & $71,42 \%$ & 4 & $28,57 \%$ \\
\hline & $\begin{array}{l}\text { Produção e } \\
\text { Transporte do } \\
\text { Alimento }\end{array}$ & 12 & $42,85 \%$ & 16 & $57,14 \%$ \\
\hline & Documentação & 0 & $0 \%$ & 17 & $100 \%$ \\
\hline \multirow{5}{*}{$\mathrm{B}-\mathbf{1}^{\mathrm{a}}$ visita } & $\begin{array}{l}\text { Edificações e } \\
\text { Instalações }\end{array}$ & 28 & $36,84 \%$ & 48 & $63,15 \%$ \\
\hline & $\begin{array}{l}\text { Equipamentos, } \\
\text { Móveis e Utensílios }\end{array}$ & 10 & $47,61 \%$ & 11 & $52,38 \%$ \\
\hline & Manipuladores & 8 & $57,14 \%$ & 6 & $42,85 \%$ \\
\hline & $\begin{array}{l}\text { Produção e } \\
\text { Transporte do } \\
\text { Alimento }\end{array}$ & 11 & $39,28 \%$ & 17 & $60,71 \%$ \\
\hline & Documentação & 0 & $0 \%$ & 17 & $100 \%$ \\
\hline \multirow{5}{*}{$B-2^{a}$ visita } & $\begin{array}{l}\text { Edificações e } \\
\text { Instalações }\end{array}$ & 27 & $35,52 \%$ & 48 & $64,47 \%$ \\
\hline & $\begin{array}{l}\text { Equipamentos, } \\
\text { Móveis e Utensílios }\end{array}$ & 10 & $47,61 \%$ & 11 & $52,38 \%$ \\
\hline & Manipuladores & 8 & $57,14 \%$ & 6 & $42,85 \%$ \\
\hline & $\begin{array}{l}\text { Produção e } \\
\text { Transporte do } \\
\text { Alimento }\end{array}$ & 12 & $42,85 \%$ & 16 & $57,14 \%$ \\
\hline & Documentação & 0 & $0 \%$ & 17 & $100 \%$ \\
\hline
\end{tabular}

Fonte: Dados coletados pelo autor (2018).

As médias dos percentuais obtidos na Tabela 2 foram realizadas e o desvio padrão então determinado, uma vez que cada local passou por duas visitas. Deste modo, Figura 1 representa as médias e o desvio padrão dos referidos módulos mencionados em ambas as padarias, que levaram ao resultado final de cada um conforme seu percentual de conformidades e inconformidades encontradas. 


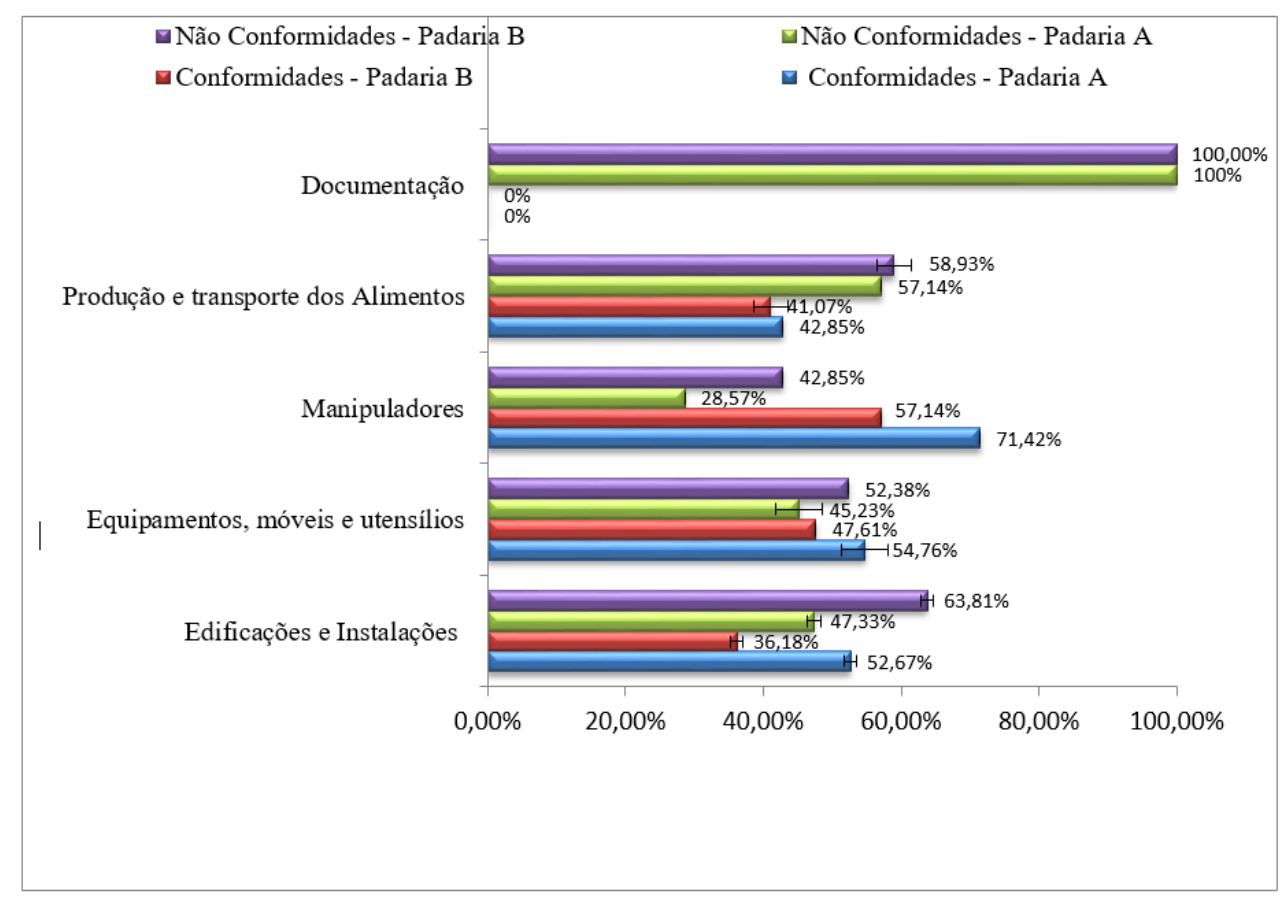

Figura 1 - Resultado das médias e desvio padrão dos percentuais de conformidades e inconformidades às boas práticas de fabricação encontradas em cada módulo das respectivas padarias analisadas no Município de Campinas - SP.

Fonte: Dados coletados pelo autor (2018).

Conforme representado na Figura 1, é possível observar:

No módulo de Documentação, ambas as padarias obtiveram a mesma média percentual de $0 \%$ de conformidades aos itens avaliados e o mesmo desvio padrão \pm 0 , assim como às inconformidades encontradas, onde a média percentual foi de $100 \% \mathrm{com}$ um desvio padrão de \pm 0 , sendo classificadas como "RUIM" quanto ao atendimento as boas práticas de fabricação, enquadrando-se em Grupo 3 (0 a 50\% de atendimento aos itens).

No módulo de Produção e Transporte dos Alimentos a padaria A, obteve uma média percentual de $42,85 \%$ de conformidades aos itens avaliados com um desvio padrão de \pm 0 , enquanto a padaria B obteve uma média percentual de $41,07 \%$ com um desvio padrão de $\pm 0,025243712$. Ao serem avaliadas quanto às inconformidades encontradas, a padaria A apresentou uma média percentual de $57,14 \%$ com um desvio padrão de \pm 0 e a padaria B uma média percentual de 58,93\% com um desvio padrão de $\pm 0,025243712$, sendo classificadas como "RUIM" quanto ao atendimento as boas práticas de fabricação, enquadrando-se em Grupo 3 novamente ( 0 a $50 \%$ de atendimento aos itens).

No módulo de Manipuladores, a padaria A, obteve uma média percentual de $71,42 \%$ de conformidades aos itens avaliados com um desvio padrão de \pm 0 , enquanto a padaria B obteve uma média percentual de $57,14 \%$ com um desvio padrão de \pm 0 . Ao serem avaliadas quanto às inconformidades encontradas, a padaria $\mathrm{A}$ apresentou uma média percentual de $28,57 \%$ com um desvio padrão de \pm 0 e a padaria $\mathrm{B}$ uma média percentual de $42,85 \%$ com um desvio padrão de \pm 0 , sendo classificadas como "REGULAR" quanto ao atendimento as boas práticas de fabricação, enquadrando-se em Grupo 2 (51 a $75 \%$ de atendimento aos itens).

No módulo de Equipamentos, móveis e utensílios, a padaria A, obteve uma média percentual de $54,76 \%$ de conformidades aos itens avaliados com um desvio padrão de \pm 0,033658283, enquanto a padaria B obteve uma média percentual de 47,61\% com um desvio padrão de \pm 0 . Ao serem avaliadas quanto às inconformidades encontradas, a 
padaria A apresentou uma média percentual de $45,23 \%$ com um desvio padrão de \pm 0,033658283 e a padaria B uma média percentual de 52,28\% com um desvio padrão de \pm 0 . Deste modo, a padaria A foi classificada como "REGULAR" quanto ao atendimento as boas práticas de fabricação, enquadrando-se em Grupo 2 (51 a $75 \%$ de atendimento aos itens) e a padaria B como "RUIM" enquadrando-se em Grupo 3 (0 a 50\% de atendimento aos itens).

No módulo de Edificações e Instalações a padaria A, obteve uma média percentual de $52,67 \%$ de conformidades aos itens avaliados com um desvio padrão de $\pm 0,00940452$, enquanto a padaria B obteve uma média percentual de $36,18 \%$ com um desvio padrão de $\pm 0,00933381$. Ao serem avaliadas quanto às inconformidades encontradas, a padaria $\mathrm{A}$ apresentou uma média percentual de 47,33\%, com um desvio padrão de $\pm 0,009475231$ e a padaria B uma média percentual $63,81 \%$, com um desvio padrão de $\pm 0,00933381$. Deste modo, a padaria A foi classificada como "REGULAR" quanto ao atendimento as boas práticas de fabricação, enquadrando-se em Grupo 2 novamente (51 a $75 \%$ de atendimento aos itens) e a padaria B como "RUIM" enquadrando-se em Grupo 3 novamente ( 0 a $50 \%$ de atendimento aos itens).

Ao avaliar de forma geral, as duas panificadoras incluídas neste estudo quanto ao seu percentual de conformidades encontradas, considerou-se a somatória de todos os itens avaliados em todos os módulos. Sendo estes: itens julgados (conforme e não conforme) e itens atendidos (conforme) e mediante elaboração do mesmo cálculo referenciado na equação 1, assim como média e desvio padrão obteve-se o resultado final de conformidades $(\%)$ dos dois estabelecimentos nas duas visitas realizadas representado no Quadro 1. 
Quadro 1 - Representação da somatória total de itens julgados (conformes e não conformes) e itens atendidos (conformes) de todos os módulos de ambas as padarias, assim como resultado final de conformidades (\%) dos locais avaliados:

\begin{tabular}{|c|c|c|c|c|c|c|}
\hline Padarias & Módulos & $\begin{array}{l}\text { Itens atendidos } \\
\text { conformes }(\mathrm{C})\end{array}$ & $\begin{array}{c}\text { Somatória } \\
\text { dos itens } \\
\text { conformes de } \\
\text { todos os } \\
\text { módulos } \\
\\
\text { n }\end{array}$ & $\begin{array}{c}\text { Itens } \\
\text { julgados - } \\
\text { conformes e } \\
\text { não } \\
\text { conformes } \\
\\
\text { n }\end{array}$ & $\begin{array}{l}\text { Somatória dos } \\
\text { itens } \\
\text { conformes e } \\
\text { não conforme } \\
\text { de todos os } \\
\text { módulos } \\
\text { n }\end{array}$ & $\begin{array}{l}\text { Resultado final de } \\
\text { conformidades }\end{array}$ \\
\hline \multirow{5}{*}{$A-1^{a}$ visita } & $\begin{array}{l}\text { Edificações e } \\
\text { Instalações }\end{array}$ & 40 & \multirow{5}{*}{73 itens } & 75 & \multirow{5}{*}{155 itens } & \multirow{5}{*}{$47,09 \%$} \\
\hline & $\begin{array}{l}\text { Equipamentos, } \\
\text { móveis e utensílios }\end{array}$ & 11 & & 21 & & \\
\hline & Manipuladores & 10 & & 14 & & \\
\hline & $\begin{array}{l}\text { Produção e } \\
\text { Transporte do } \\
\text { Alimento } \\
\end{array}$ & 12 & & 28 & & \\
\hline & Documentação & 0 & & 17 & & \\
\hline \multirow{5}{*}{$A-2^{a}$ visita } & $\begin{array}{l}\text { Edificações e } \\
\text { Instalações } \\
\end{array}$ & 39 & \multirow{5}{*}{73 itens } & 75 & \multirow{5}{*}{155 itens } & \multirow{5}{*}{$47,09 \%$} \\
\hline & $\begin{array}{l}\text { Equipamentos, } \\
\text { móveis e utensílios }\end{array}$ & 12 & & 21 & & \\
\hline & Manipuladores & 10 & & 14 & & \\
\hline & $\begin{array}{l}\text { Produção e } \\
\text { Transporte do } \\
\text { Alimento } \\
\end{array}$ & 12 & & 28 & & \\
\hline & Documentação & 0 & & 17 & & \\
\hline \multirow{5}{*}{ B - $1^{\mathrm{a}}$ visita } & $\begin{array}{l}\text { Edificações e } \\
\text { Instalações } \\
\end{array}$ & 28 & \multirow{5}{*}{57 itens } & 76 & \multirow{5}{*}{156 itens } & \multirow{5}{*}{$46,79 \%$} \\
\hline & $\begin{array}{l}\text { Equipamentos, } \\
\text { móveis e utensílios }\end{array}$ & 10 & & 21 & & \\
\hline & Manipuladores & 8 & & 14 & & \\
\hline & $\begin{array}{l}\text { Produção e } \\
\text { Transporte do } \\
\text { Alimento }\end{array}$ & 11 & & 28 & & \\
\hline & Documentação & 0 & & 17 & & \\
\hline \multirow{5}{*}{ B $-2^{\mathrm{a}}$ visita } & $\begin{array}{l}\text { Edificações e } \\
\text { Instalações } \\
\end{array}$ & 27 & \multirow{5}{*}{57 itens } & 76 & \multirow{5}{*}{156 itens } & \multirow{5}{*}{$46,79 \%$} \\
\hline & $\begin{array}{l}\text { Equipamentos, } \\
\text { móveis e utensílios }\end{array}$ & 10 & & 21 & & \\
\hline & Manipuladores & 8 & & 14 & & \\
\hline & $\begin{array}{l}\text { Produção e } \\
\text { Transporte do } \\
\text { Alimento }\end{array}$ & 12 & & 28 & & \\
\hline & Documentação & 0 & & 17 & & \\
\hline
\end{tabular}

Fonte: Dados coletados pelo autor (2018).

A Figura 2 representa o resultado final de conformidades encontradas nas respectivas padarias avaliadas, através das médias dos percentuais obtidos na tabela $4 \mathrm{e}$ seu desvio padrão. 


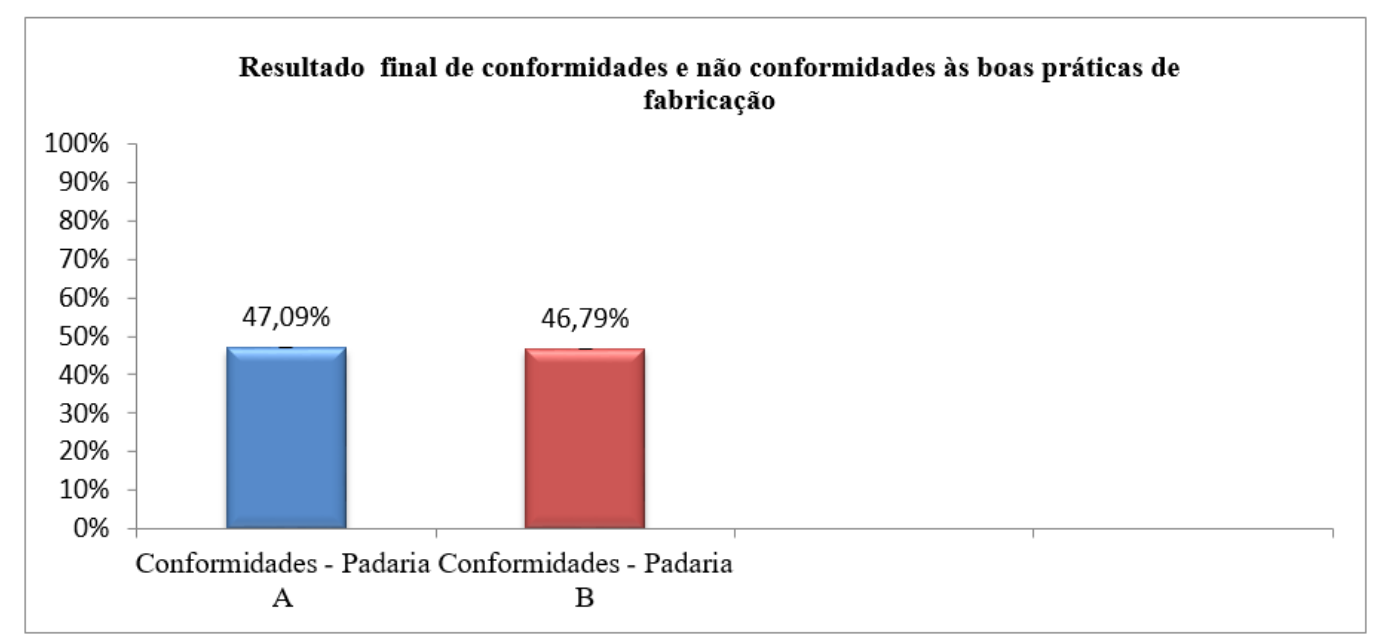

Figura 2 - Resultado final de conformidades encontradas nas respectivas padarias analisadas, considerando a somatória de todos os módulos avaliados representado em médias e desvio padrão.

Fonte: Dados coletados pelo autor (2018).

Conforme Figura 2, podemos observar que a padaria A obteve uma média percentual de $47,09 \%$ de conformidades aos itens avaliados com um desvio padrão de \pm 0 e a padaria B uma média percentual de $46,79 \%$ com um desvio padrão de \pm 0 . Deste modo, ambas as padarias foram classificadas de forma geral como "RUIM", quanto ao atendimento as boas práticas de fabricação, enquadrando-se em Grupo 3 (0 a 50\% de atendimento aos itens).

Em seguida, uma análise qualitativa adicional foi realizada com os proprietários de ambas as padarias por meio de um questionário, tendo por objetivo final esclarecer a visão destes quanto às inconformidades evidenciadas. Deste modo, as cinco perguntas elaboradas e as respostas obtidas por elas, encontram-se transcritas abaixo.

1. Você nunca pensou em contratar uma empresa de consultoria sanitária ou ainda, ter uma nutricionista fixa para te auxiliar em toda a parte estrutural e em toda a documentação necessária além das boas práticas de fabricação?

Resposta Padaria A: "Sim, no começo eu e os demais proprietários pensamos isto, mais em virtude do cenário econômico tivemos uma queda muito grande nas vendas, o que nos impossibilitou de fazer tal investimento".

Resposta Padaria B: "Na verdade sim, porém devido à situação financeira que eu e os demais sócios vivemos no momento isto nos impossibilitou de agregar mais custos. Então, estamos tentando nos adequar para que em um futuro bem próximo a contratação de uma empresa de consultoria seja realizada, mas, a respeito de uma Nutricionista fixa eu acho desnecessário pelo porte da minha empresa".

2. Você está ciente que existem documentações obrigatórias perante a vigilância sanitária que não existem no local? Se sim, não tem interesse em se adequar a legislação?

Resposta Padaria A: "Sim, estou ciente e tenho vontade em me adequar futuramente, a partir da nossa melhora econômica e com o mercado aquecendo novamente nos queremos trabalhar com tudo em ordem, dentro da lei".

Resposta Padaria B: "Sim estou ciente de que faltam documentações no local e tenho interesse em estar me adequando, mas voltaria na pergunta anterior onde digo que a 
questão financeira no momento não está boa e que não estou em condições momento, devido a grande crise financeira”.

3. O que leva a dificuldade de adequação da estrutura física do local? São recursos financeiros ou a dificuldade de realizar modificações em um prédio alugado e não próprio?

Resposta Padaria A: "Alguns sim e outras não, esses fatores são bastante significativos, porém algumas adequações nós conseguimos fazer e executar, já outras dependem realmente da autorização dos proprietários do prédio”.

Resposta Padaria B: "O principal motivo sempre irá cair na parte financeira, lógico que o prédio também é alugado e toda mudança tem que ter uma autorização dos responsáveis, sendo que várias coisas que já tentei fazer no local, não fui autorizado”.

4. Você acredita que a falta de capacitação / treinamento de pessoal, possa estar interferindo em uma boa parte nas inconformidades encontradas, ou seja, o não atendimento das boas práticas? Acredita que treinamentos seriam necessários?

Resposta Padaria A: "Algumas eu concordo que possa ser por falta de capacitação da equipe, mas por outro lado os funcionários também são orientados por mim e pelos demais sócios com relação a algumas boas práticas, claro que não sabemos todas, mas creio que se tivesse algum treinamento específico, essas inconformidades seriam bem menores".

Resposta Padaria B: "Todo treinamento é bem-vindo, principalmente nesta área. A necessidade das capacitações é clara uma vez que trará benefícios e ajudas para empresa, sendo assim os funcionários precisam de treinamento, assim como eu e os demais sócios. Desta forma a necessidade de treinamentos existe sim e nós precisamos deste auxilio, mas voltando em todas as questões já ditas, tudo gira em torno de dinheiro e a situação nossa no momento não é a mais favorável”.

5. Você acha que a criação de planilhas de controle, sejam estas de recebimento de mercadorias, temperatura de equipamentos e alimentos, higienização, vencimentos e outras, seriam uma forma de auxílio a melhoria das boas práticas de fabricação?

Resposta Padaria A: "Sim seria, pois isto bateria de frente com a nossa intenção que é aumentar a qualidade dos produtos oferecidos ao consumidor final. Então tendo estes controles, eu consigo uma garantia quase de $100 \%$ que o alimento será bem feito e chegará à mesa do consumidor em perfeitas condições”.

Resposta Padaria B: "Com certeza, inclusive esta é a maneira correta de se trabalhar, porque é a maneira que temos pra manter o controle da validade dos nossos produtos e da qualidade também, como produtos bem embalados, com adequados padrões de temperatura, então isso só vem a nos agregar”.

\section{DISCUSSÃO}

Com o processo de globalização e com a expansão de diversos setores na área da alimentação, percebe-se a necessidade do controle higiênico-sanitário dos locais de produção e venda dos produtos, a fim de minimizar e controlar todos os perigos químicos, físicos e biológicos que possam levar a doenças transmitidas por alimentos. Desta forma, as padarias por serem um dos locais que mais cresceram nos últimos anos e por receber diariamente milhares de pessoas, necessitam de controles rigorosos durante o processo produtivo que garantam a qualidade efetiva de seus produtos. Por isso, sabendo que a maioria das panificadoras ainda trabalha de forma artesanal e que podem trazer riscos graves a saúde do consumidor, o presente estudo teve por objetivo avaliar as boas práticas 
de fabricação de dois estabelecimentos e verificou a ausência de qualquer tipo de controle em ambos os locais devido o alto número de inconformidades encontradas, levando assim a preocupantes resultados onde podemos destacar que nenhuma dentre as panificadoras avaliadas foram classificadas em Grupo 1 - "BOM", considerando o de melhor atendimento as boas práticas de fabricação. Portanto descreve-se a seguir os principais problemas que levaram aos baixos percentuais de conformidades obtidos em cada módulo e influenciaram na classificação final das panificadoras.

Quanto ao módulo de documentação, verificou-se que nenhuma dentre as panificadoras avaliadas apresentavam manual de boas práticas de fabricação e procedimentos operacionais padronizados (POP), documentos estes que melhor capacitariam seus colaboradores na execução de suas atividades, garantindo uma melhor otimização e desempenho da mão de obra e adequação dos estabelecimentos no quesito documentação ao que é exigido e estabelecido pelo órgão fiscal de vigilância sanitária. Deste modo, podemos salientar que o objetivo principal dos procedimentos operacionais padronizados (POP) é estabelecer instruções sequenciais para a realização de operações rotineiras e específicas na produção, armazenamento e transporte dos alimentos e o objetivo principal do manual de boas práticas é descrever os procedimentos adotados por um determinado setor de alimentação, a fim de atender os requisitos relacionados às boas práticas, conforme preconizado pela $\mathrm{RDC} \mathrm{n}^{\circ}$ 275/2002. Assim sendo, documentos que auxiliariam no atendimento as condições higiênico-sanitárias necessárias para o adequado processamento / industrialização dos alimentos (AGÊNCIA NACIONAL DE VIGILÂNCIA SANITÁRIA - ANVISA, 2002).

O módulo de Produção e Transporte dos alimentos obteve percentuais de conformidades inferiores a $50 \%$ por isso pôde-se observar que os aspectos que mais contribuíram para tantas inconformidades encontradas e o baixo percentual de adequação obtido em ambas as padarias foram: a ausência de locais específicos para o recebimento de suas mercadorias, a falta de conferência das mercadorias no ato do recebimento com inutilização de planilhas de controle, a ausência de rotulagem nutricional dos produtos produzidos, o armazenamento e o recebimento de produtos realizado de maneira inadequada e a ausência de separação das áreas de pré-preparo e preparo dos alimentos. Desta forma, podemos verificar que a falta de inspeção dos produtos no ato da entrega, é algo preocupante, uma vez que produtos fora do peso, validade e com inadequados padrões de qualidade e temperatura possam estar sendo recebidos pelos locais. Ainda, a rotulagem nutricional dos produtos é obrigatória perante legislação sanitária e deve estar adequada por ser direito do consumidor obter informações dos produtos produzidos e embalados em sua ausência, assim como o adequado armazenamento dos produtos e a divisão das áreas de pré-preparo e preparo dos estabelecimentos, por meio de barreiras físicas ou técnicas evitando assim possíveis contaminações cruzadas. Consequentemente, ao avaliar os problemas evidenciados neste módulo com outros estudos realizados por Guimarães et al (GUIMARÃES; FIGUEIREDO, 2010), Bramorski et al (BRAMORSKI et al., 2004) e São José et al (DE SÃO JOSÉ; COELHO; FERREIRA, 2011), observouse que estes também apresentaram diversificados problemas, sendo alguns compatíveis ao encontrado no estudo desenvolvido. Dentre eles podemos destacar: a ausência de estrados para o adequado armazenamento dos produtos não perecíveis, permitindo que estes ficassem em contato direito com o chão, condições higiênico-sanitárias da matéria prima, assim como o seu recebimento e armazenamento deficientes, alimentos armazenados em freezers e geladeiras com ausência de rotulagem, procedência e proteção e alimentos produzidos e deixados em temperatura ambiente por períodos prolongados de exposição, apontando assim comprometimento da qualidade dos produtos preparados. 
O módulo de Manipuladores apesar de apresentar na seção de resultados o maior percentual de conformidades às boas práticas de fabricação em ambos os estabelecimentos, também apresentou inúmeras inconformidades, sendo estas: ausência de procedimentos de higienização das mãos, ausência de alguns equipamentos de proteção individual (EPI), ausência de supervisores comprovadamente capacitados para fiscalização do atendimento as boas práticas local, ausência de capacitações aos manipuladores e uso contínuo de adornos. Notou-se ainda apenas na padaria B falta de cartazes sobre o correto procedimento de higienização das mãos, assim como alguns colaboradores trabalhando com uniformização incompleta, sendo observado uso de calçados abertos e camisetas convencionais. Enquanto isso, na padaria A todos os funcionários faziam uso de uniformes completos, porém, em segunda visita realizada ao local, um deles apresentou este em ruim estado de conservação e higiene, ocasionando altos riscos de contaminação cruzada. Estudos realizados por Guimarães et al (GUIMARÃES; FIGUEIREDO, 2010); Germano et al (GERMANO et al., 2009) e Cardoso L. et al (CARDOSO, L.; ARAÚJO, 2001) apontam problemas semelhantes, onde estes relacionaram a falta de hábitos higiênicos, a inexistência de treinamentos, a ausência de procedimentos de higienização das mãos, a ingestão de alimentos durante a manipulação, a negligência ao risco de contaminação cruzada, o uso de adornos e a falta de hábitos em utilizar uniformes completos e equipamentos de proteção individual EPI's, alguns dos principais problemas encontrados. Pode-se então afirmar que as boas práticas de fabricação são a base para um controle de qualidade eficaz. Por isso, percebese a relevância da conscientização dos manipuladores de alimentos, quanto a este conceito.

Após a realização das visitas às panificadoras, notou-se no módulo de Equipamentos, móveis e utensílios que a padaria A obteve os melhores percentuais de conformidades quando comparada a padaria B. Sendo assim, as inconformidades evidenciadas neste módulo foram: ausência de registros de calibração, temperatura dos equipamentos e manutenção, armazenamento de utensílios ocorrendo de maneira inapropriada, disponibilização de equipamentos próximos às paredes e a ausência de profissionais comprovadamente capacitados para as etapas de limpeza. Na padaria B os maquinários apresentavam ruim estado de conservação, onde alguns encontravam-se com pontos de ferrugem, descascamentos e ausência de proteção dos motores, onde este problema não foi evidenciado na padaria A. Constatou-se ainda, a ausência de qualquer tipo de controle, que venha garantir a qualidade do produto oferecido ao consumidor, uma vez que nenhum equipamento utilizado para sua produção sofria manutenção ou calibração preventiva, e muito menos controles eram feitos periodicamente para assegurar seu correto funcionamento, sendo os utensílios totalmente expostos à contaminação e os procedimentos de limpeza não realizados de maneira periódica. Logo, estudo realizado por Bramorski et al (BRAMORSKI et al., 2004), observou que 54\% dos estabelecimentos avaliados receberam conceito deficiente às boas práticas de fabricação e os fatores que resultaram a este percentual obtido foram: a má conservação e higienização dos equipamentos, a superlotação de freezers, geladeiras e balcões frigoríficos com diferentes gêneros alimentícios, a ausência de controles de temperaturas, o mau estado de conservação dos utensílios e a utilização de móveis de madeira - material de bastante absorção e difícil higienização, propiciando a proliferação de micro-organismos. Deste modo, podemos observar que as inconformidades encontradas, não se limitam apenas ao município e estado estudado, uma vez que foram evidenciadas na literatura inconformidades semelhantes.

Por fim, ao avaliar o módulo de Edificações e instalações das panificadoras estudadas, pôde-se verificar novamente que a padaria A obteve os melhores percentuais 
de conformidades ao ser comparada a padaria B. Constatou-se de forma geral que as inconformidades encontradas, foram: pisos e paredes com inadequado estado de conservação, ralos com acúmulos de resíduos, ausência de borrachas de vedação na parte inferior das portas e falhas em seu revestimento, facilitando acesso de vetores e pragas urbanas, presença de telas milimétricas não removíveis dificultando adequada higienização, ausência de portas com fechamento automático, ausência de chuveiros em quantidade suficiente a todos os funcionários nas instalações sanitárias, inexistência de registros de manutenção e higienização dos equipamentos que permitem circulação de ar, ausência de filtros nos exaustores, falta de profissionais comprovadamente capacitados para as etapas de limpeza, ausência de registros de higienização de equipamentos e ambientes, ausência de controles contra pragas e vetores urbanos, ausência de higienização dos reservatórios de água e laudos laboratoriais que comprovem a potabilidade da água, ausência de lavatórios nas áreas de manipulação, tetos de materiais não lisos e a presença de objetos em desuso em áreas internas. Ainda, podemos mencionar que algumas das inconformidades descritas se diferem entre as padarias analisadas, como por exemplo:

A padaria A apresentava sua área externa livre de focos de insalubridade e objetos em desuso, enquanto a padaria B possuía esteiras de pães, ferros e madeiras em desuso, sendo estes atrativos para vetores e pragas urbanos. Tal fato contraria o estabelecido na RDC n ${ }^{\circ}$ 216/2004 (BRASIL; AGÊNCIA NACIONAL DE VIGILÂNCIA SANITÁRIA - ANVISA, 2004), na qual dispõe que as áreas internas e externas do estabelecimento devem estar livres de objetos em desuso ou estranhos ao ambiente.

$\mathrm{O}$ piso da padaria $\mathrm{B}$ encontra-se em inadequado estado de conservação, com presença de trincas e rachaduras, assim como o seu teto que apresentava bolor próximo ao exaustor da produção, sendo o ideal conforme RDC ${ }^{\circ}$ 216/2004 (BRASIL; AGÊNCIA NACIONAL DE VIGILÂNCIA SANITÁRIA - ANVISA, 2004), pisos, paredes e tetos com revestimento liso, impermeáveis, laváveis e mantidos sempre íntegros, conservados, livres de rachaduras, trincas, goteiras, vazamentos, infiltrações, bolores e descascamentos.

Algumas portas da padaria B possuíam sistema de fechamento automático, enquanto a padaria A não possuía nenhuma, facilitando contato manual para abertura, auxiliando em maiores contaminações. Conforme a Portaria CVS 5/2013 (2013), as portas devem ser mantidas ajustadas aos batentes e quando localizadas nas áreas de preparação e armazenamento de alimentos estas devem ser dotadas de fechamento automático.

As janelas da padaria B encontravam-se inadequadas, onde às localizadas na cozinha da área produtiva apresentavam vidros quebrados, podendo estes ocasionar possíveis acidentes de trabalho.

As instalações sanitárias masculinas da padaria A não eram isoladas da área produtiva, sendo localizadas dentro da produção, com risco altíssimo de contaminação biológica dos produtos produzidos, enquanto a padaria $\mathrm{B}$ encontra-se adequada neste quesito, porém, possuía sanitários com pouca ventilação e iluminação, desprovidos de materiais higiênicos e ausentes de lixeira com tampa e pedal. Portanto, ao avaliar estudo similar desenvolvido por Guimarães et al (GUIMARÃES; FIGUEIREDO, 2010), podemos constatar resultados parecidos onde as panificadoras avaliadas apresentavam instalações sanitárias muito próximas da área de fabricação dos seus produtos, os vasos sanitários eram bastante desgastados, as portas não possuíam molas com dispositivo automático para o seu fechamento e as lixeiras não eram dotadas de tampa e acionamento por pedal. 
As luminárias da padaria $\mathrm{B}$ eram fluorescentes e não protegidas contra quedas e explosões, enquanto a padaria A apresentava esta proteção. Conforme ABERC (Manual ABERC de Práticas de Elaboração e Serviço de Refeições para Coletividades, 1999) as lâmpadas devem possuir sistemas de segurança contra quedas e explosões acidentais.

A ventilação e circulação de ar da padaria $B$ não eram capazes de garantir a adequada circulação de ar e a ausência de contaminantes ao local, uma vez que o exaustor mecânico da área produtiva encontrava-se totalmente sujo no dia da inspeção, podendo ocasionar contaminação aos alimentos produzidos durante a aspersão de ar. Conforme a legislação CVS 5/2013 (2013), o sistema de ventilação deve garantir adequado conforto térmico, a renovação do ar e a manutenção do ambiente livre de fungos, gases, fumaça, gordura e condensação de vapores e fluxo de ar deve ser direcionado da área limpa para a suja não ocasionando contaminações.

Os produtos de limpeza embora guardados em locais adequados a maior parte do seu tempo, foram encontrados em segunda visita realizada na padaria A, sob a pia da produção, podendo estes ocasionar possíveis contaminações químicas aos produtos produzidos.

Para se concluir as inadequações encontradas, verificou-se que os recipientes de coleta de resíduos disponibilizados no interior da padaria B, não possuíam tampa e pedal, ficando abertos e totalmente expostos, enquanto na padaria $\mathrm{A}$, estes recipientes eram totalmente adequados. Segundo Fonseca et al (FONSECA et al., 2010), a permanência dos recipientes de coleta de resíduos sem tampa favorece a proliferação de vetores como insetos e roedores e consequente contaminação dos alimentos preparados.

Segundo Bramorski et al (BRAMORSKI et al., 2004); Cardoso L et al (CARDOSO, L.; ARAÚJO, 2001) e Cardoso AB et al (CARDOSO, A. B. et al., 2005), os resultados mais insatisfatórios obtidos em seus estudos no módulo de edificações e instalações foram: condições de manutenção e limpeza inadequadas de pisos, paredes e tetos, ausência de higienização reservatórios de água, ausência de lavatórios nas áreas de manipulação, ausência de materiais adequados para o correto procedimento de limpeza e desinfecção, presença de materiais impróprios nas áreas como madeiras e metais enferrujados, precariedade do estado de conservação e manutenção predial da área de produção, ausência de telas de proteção nas janelas, instalações sanitárias mal higienizadas, desprovidas de sabonete líquido e toalha descartável e acondicionamento indevido dos resíduos, em lixeiras sem tampa e pedal.

$\mathrm{Na}$ análise qualitativa, foi possível observar que na maioria das perguntas apresentadas anteriormente, o fator econômico foi o mais relevante e mencionado pelos proprietários, encontrando-se presente na maioria das respostas. Por isso, pode-se verificar que para os proprietários boa parte das inconformidades encontradas parte da ausência de recursos financeiros, o qual não permite a contratação de uma empresa de consultoria sanitária ou de uma nutricionista fixa para os locais, o qual possa auxiliá-los em toda parte de documentação, estrutura física, boas práticas, implantação de controles e capacitações periódicas, fatores estes que auxiliaram nas inconformidades encontradas e que foram fundamentais para obtenção dos baixos percentuais de conformidades obtidos.

Os proprietários acreditam que a presença de planilhas de controle, que as capacitações periódicas e até a presença de uma empresa de consultoria, seriam fatores primordiais para as melhorias da empresa, pois auxiliariam na redução das inconformidades atualmente evidenciadas. Porém, nota-se que o cenário econômico atualmente presente, esteja interferindo drasticamente na aquisição dos profissionais capacitados para o auxílio destes estabelecimentos, colocando em risco a qualidade dos alimentos produzidos, por falta de controles. 
Assume-se que, tanto a amostra populacional quanto o tempo de observação aqui descritos foram consideravelmente reduzidos e que as inconformidades apontadas apenas nas duas panificadoras localizadas no Município de Campinas-SP não são suficientes para refletir a realidade de todas as panificadoras localizadas neste Município. Sendo assim, sugere-se a realização de novos estudos mais bem controlados, com um número amostral mais considerável, assim como mais visitas aos locais para elucidação das possíveis falhas observadas, com um maior tempo de observação e realizados em diferentes tipos de panificadoras de acordo com porte e poder aquisitivo, visando assim verificar se o fenômeno aqui apresentado poderá se refletir em maior escala, e se ele se diferenciará de acordo com a localização do estabelecimento.

\section{CONCLUSÃO}

A partir dos resultados encontrados com a lista de verificação (check-list) e com as respostas obtidas pelas perguntas realizadas, conclui-se que o presente trabalho demonstrou elevado índice de inconformidades nos estabelecimentos inspecionados, não possuindo condições higiênico-sanitárias satisfatórias, para produção segura de seus alimentos. Portanto, podemos observar que a padaria A, tanto ao ser avaliada de forma geral, como ao ser avaliada individualmente em seus módulos, obteve os maiores percentuais de atendimento as boas práticas de fabricação enquanto a padaria B obteve os piores percentuais, sendo classificada em quatro dos cinco módulos como "RUIM", embora nenhuma delas tenham sido enquadradas em Grupo 1 - BOM (76 a 100\% de atendimento aos itens avaliados). Observa-se que de todos os módulos avaliados em ambas as padarias o que apresentou o maior percentual de adequação, foi o módulo de manipuladores e o que apresentou o maior percentual de inadequação, foi o módulo de documentação.

Acredita-se que o trabalho aqui desenvolvido sirva de forma grandiosa para criação de campanhas futuras de esclarecimentos para melhorias dos estabelecimentos, assim como o desenvolvimento de novos trabalhos na área, com um número amostral maior de panificadoras no município de Campinas-SP. Entretanto, a capacitação inicial dos envolvidos nas etapas produtivas, sobre higiene e manipulação segura de alimentos se faz necessária como pontapé inicial para as adequações das boas práticas, assim como um futuro auxílio de profissionais capacitados e uma empresa de consultoria alimentar, os quais possam implantar o Programa de Boas Práticas de Fabricação - BPF, orientando os responsáveis em toda a parte de documentação, estrutura física e implantação de controles e registros, a fim de fornecer alimentos seguros e de qualidade sanitária e nutricional, livre de perigos que possam comprometer a saúde do consumidor.

\section{REFERÊNCIAS}

APLEVICZ, K. S.; SANTOS, L. E. S.; BORTOLOZO, E. A. F. Q. Boas Práticas de Fabricação em serviços de alimentação situados em região turística do Estado do Paraná. Revista Brasileira de Tecnologia Agroindustrial, v. 4, n. 2, p. 122-131, 2010.

BRAMORSKI, A. et al. Perfil higiênico-sanitário de panificadoras e confeitarias do município de Joinville, SC. Hig. aliment, v. 18, n. 123, p. 37-41, 2004.

BRASIL. Centro de Vigilância Sanitária - Portaria CVS 5. , 2013, Sec. 1, p. 32-35. Disponível em: <http://www.cvs.saude.sp.gov.br/cvs.asp>. Acesso em: 8 set. 2018.

BRASIL; AGÊNCIA NACIONAL DE VIGILÂNCIA SANITÁRIA - ANVISA. Resolução da Diretoria Colegiada - RDC $\mathrm{n}^{0}$ 216. , 2004. Disponível em: <http://portal.anvisa.gov.br>. Acesso em: 8 set. 2018. 
BRASIL; AGÊNCIA NACIONAL DE VIGILÂNCIA SANITÁRIA - ANVISA. Resolução da Diretoria Colegiada - RDC $\mathrm{n}^{\mathrm{o}}$ 275. , 2002. Disponível em: <http://portal.anvisa.gov.br>. Acesso em: 8 set. 2018.

CARDOSO, A. B. et al. Avaliação das condições higiênico-sanitárias de panificadoras. Hig. aliment, v. 19, n. 130, p. 45-49, 2005.

CARDOSO, L.; ARAÚJO, W. M. Perfil higiênico-sanitário das panificadoras no Distrito Federal. Hig. aliment, v. 15, n. 83, p. 32-42, 2001.

COELHO, M. et al. Avaliação das Boas práticas através de check-list aplicado em restaurantes self-service da região central de Maringá, Estado do Paraná. Blucher Biochemistry Proceedings, v. 1, n. 1, p. 75-76, 2015.

COUTO, S. R. M. et al. Diagnóstico higiênico-sanitário de uma unidade hoteleira de produção de refeições coletivas. Hig. aliment, v. 19, n. 131, p. 15-18, 2005.

DE SÃO JOSÉ, J. F. B.; COELHO, A. Í. M.; FERREIRA, K. R. Avaliação das boas práticas em unidade de alimentação e nutrição no município de Contagem-MG. Brazilian Journal of Food \& Nutrition/Alimentos e Nutrição, v. 22, n. 3, p. 479-487, 2011.

DOS SANTOS, M. DE O. B. et al. Adequação de restaurantes comercias às boas práticas. Higiene Alimentar, v. 24, n. 190/191, p. 45-49, 2010.

FERRAZ, R. R. N. et al. Ocorrência de produtos alimentares fora da validade, em vending machines de empresa paulista. Hig. aliment, v. 27, n. 226/227, p. 63-67, 2014.

FONSECA, M. P. DA et al. Avaliação das condições físicas e funcionais de restaurantes comerciais para implementação das boas práticas. Alim. Nutr., Araraquara, v. 21, n. 2, p. 251-257, 2010.

GERMANO, M. I. S. et al. Padarias: a visão do consumidor sobre as condições higiênicosanitárias. Higiene Alimentar, v. 23, n. 172/173, p. 87-93, 2009.

GUIMARÃES, S. L.; FIGUEIREDO, E. L. Avaliação das condições higiênico-sanitárias de panificadoras localizadas no município de Santa Maria do Pará-PA. Revista Brasileira de Tecnologia Agroindustrial, v. 4, n. 2, p. 198-206, 2010.

Manual ABERC de Práticas de Elaboração e Serviço de Refeições para Coletividades. $4^{\mathrm{a}}$ ed ed. São Paulo: ABERC, 1999. 